\title{
SOBRE ARGUMENTOS TÓPICOS DIALÉTICOS E RETÓRICOS NA “CONSOLAÇÃO DA FILOSOFIA”*
}

\author{
Luana Talita da Cruz** \\ http://orcid.org/0000-0003-1206-3722 \\ luanadacruz@ymail.com
}

RESUMO Este trabalho tem por objetivo apresentar os tipos de Argumentos Tópicos reconhecidos por Boécio, apontando suas diferenças quanto à disciplina a que pertencem. A partir disso, pretende-se considerar seu uso na "Consolação", ressaltando que a utilização dessa forma de argumento possui, de acordo com o próprio filósofo, implicações sobre o objetivo do autor ao escrever o texto. Tendo sido sua última obra e escrita tão próxima ao estudo que realizou dos textos sobre os Tópicos, cuja pretensão era de, mais tarde, harmonizar com as demais partes da lógica para fortalecê-la conforme parece propor em ambos os escritos sobre o tema, pareceria pertinente supor que Boécio utilizaria esse tipo de argumento para encontrar as inferências mais adequadas ao seu discurso, dando-lhe força e deixando clara sua intenção por meio da estrutura formal a que recorreu.

Palavras-chave Argumentos Tópicos, "Consolação da Filosofia”, Lógica Medieval, Boécio.

ABSTRACT This paper aims to present the types of Topical Arguments recognized by Boethius, presenting their differences as to the discipline to which they belong. From this, it is intended to point out its use in the Consolation, emphasizing that the use of this type of arguments has, according to the

** Universidade Federal de Pelotas - UFPel. Pelotas, RS, Brasil. 
philosopher himself, implications on the author's goal for writing the text. Having been his last work and having been written so close to his study of the texts on the Topics, which he intended to harmonize later with the other parts of logic in order to strengthen it as it seems to be proposed in both of his writings on the subject, it would seem appropriate to suppose that Boethius would use this type of argument to find the most appropriate inferences to his discourse, giving it strength and making his intention clear through the formal structure to which he resorted to.

Keywords Topical Arguments, "Consolation of Philosophy”, Medieval Logic, Boethius.

\section{Introdução}

Em se tratando de Inferências Tópicas, Boécio identifica dois tipos, a saber, dialéticas e retóricas. Apesar da distinção, ambas compartilham os mesmos propósitos anteriores às suas características particulares de como produzem crença sobre aquilo que está sob consideração, que é a dupla função de encontrar argumentos e, de fato, produzir crença. Nesse sentido, é trabalho do dialético, do orador e, também, do filósofo, estar familiarizado com a forma pela qual um Tópico ${ }^{1}$ se apresenta, sabendo, a partir de sua Differentia ou Proposição Máxima, reconhecê-lo. A utilização de um Tópico Retórico ou Dialético, no entanto, apresenta particularidades que indicam tipos de discurso bastante diferentes um do outro, cuja intenção é capaz de ser reconhecida apenas por seus usos na argumentação, uma vez que a intenção do argumentador é deixada clara na escolha do recurso por meio do qual argumenta.

Assim, ao considerar a "Consolação da Filosofia", além de se ter em mente o caráter pedagógico de tal obra, é importante considerar também a estrutura mediante a qual Boécio pretende ensinar o caminho para a felicidade. Uma vez que a obra se dá por meio do diálogo dos personagens de Boécio e da Filosofia, há um debate entre dois oradores, de modo que se faz possível a utilização

1 Utilizaremos, aqui, a diferenciação de maiúsculas e minúsculas para tornar o texto mais claro. Por "Tópicos" entendemos os tratados acerca dos Tópicos, independentemente de autor, sendo, que, nesse caso, também virá acompanhado do uso de itálico, ou, ainda, o tipo de argumento, como na expressão "Argumento Tópico", enquanto que por "tópico" entendemos o locus do argumento. O mesmo princípio será aplicado à "Differentia" e "differentia", sendo a primeira aquilo que permite que se encontre o termo médio de um Argumento Tópico e a segunda um predicável. Quanto a essa diferenciação, seguimos a obra de Stump (1978) e, por questões de coesão, utilizaremos a expressão "Proposição Máxima" sempre em maiúsculas, a fim de apontar sua relação com a Differentia de um Argumento Tópico. 
de Argumentos Tópicos. Mais do que isso, ambos os personagens pretendem inspirar crença, enquanto personagens, do mesmo que o autor, também, por intermédio deles, pretende inspirar crença no leitor. Desse modo, podemos perceber que Boécio deu a si mesmo, em sua última obra, as ferramentas para a utilização de ambos os tipos de Argumentos Tópicos que ele reconhece e cuja possibilidade de uso pretendemos analisar neste artigo.

\subsection{Argumentos Tópicos Dialéticos e Retóricos}

Um Argumento Tópico é aquilo que trata de algo que está sob consideração e de onde se pode derivar o argumento apropriado à questão ou, ainda, é um tópico o que se chama de locus do argumento (cf. Boécio, 1978, Livro I, [1173d - 32], p. 30). Os Tópicos, conforme Boécio os entende, são um conjunto de argumentos que ele tenta harmonizar a partir de Aristóteles, Cícero e Temístio, os quais ele divide em Argumentos Dialéticos e Argumentos Retóricos, sendo que ele considera o tratamento que dá às Inferências Retóricas algo original. De modo geral, uma primeira divisão que Boécio reconhece acerca dos Tópicos é que Tópicos Dialéticos são utilizados no tratamento de abstrações e conceitos gerais, enquanto que Tópicos Retóricos são utilizados em casos particulares. No entanto, ambos são instrumentos do dialético e do orador, sendo que é mediante seu uso no discurso que as distinções se tornam claras. Por meio do uso, Tópicos Dialéticos e Retóricos podem ser reconhecidos, já que divergem tanto quanto à sua forma quanto ao seu propósito específico no discurso.

Ainda que um tópico sempre trate sobre algo que está sob consideração e qualquer tipo de Inferência Tópica tenha por objetivo encontrar um argumento a fim de produzir crença, “[...] a dialética está restrita à pergunta e resposta. A retórica, por outro lado, avança no assunto proposto mediante discurso ininterrupto"2 (Boécio, Livro IV, [1206C, 28- 30], pp. 79-80, tradução nossa ${ }^{3}$ ). Mais do que isso, Boécio propõe uma série de restrições estruturais aos Tópicos Retóricos que não afetam os Tópicos Dialéticos, uma vez que esses apenas se apresentam na forma de silogismos e acompanhados de uma Proposição Máxima ou Differentia. Assim, uma das mais simples diferenciações entre esses tipos

2 Tradução livre de: [...] dialectic is restricted to question and answer. Rhetoric, on the other hand, goes through the subject proposed in unbroken discourse. BOÉCIO. De topicis differentiis. In: STUMP. E. (trad.). "Boethius's De topicis differentiis", 1978, Livro IV, [1206C, 28-30], pp. 79-80.

3 Dada a indisponibilidade da edição crítica da tradução da obra "De topicis differentiis", utilizamos, aqui, as traduções de Eleanor Stump para o inglês. A fim de manter a coesão do texto, utilizaremos, também, a tradução para o inglês da "Consolação da Filosofia", por Joel C. Relihan, devido à numeração que não se encontra na tradução brasileira. 
de Tópicos é que, enquanto os Tópicos Dialéticos têm a forma de silogismos completos, os Tópicos Retóricos têm a forma de entimemas. ${ }^{4}$

Não apenas a forma dos Tópicos Dialéticos e Retóricos parte do mesmo ponto, a saber, uma proposição sob consideração, mas, simplesmente, deixam de ser o mesmo em seu uso e forma particular. Sua construção, enquanto Tópico, também se diferencia conforme e por causa do conteúdo de sua disciplina.

[...] se a dialética, de alguma forma, admite circunstâncias tais como alguma ação ou pessoas na disputa, não o faz por causa das próprias circunstâncias (principaliter), mas, sim, para transferir toda a força da circunstância para a tese discutida. No entanto, se a retórica aceita uma tese, ela é considerada hipótese. Cada uma investiga sua própria matéria e aceita a [matéria] da outra, de modo que o assunto depende da disciplina mais adequada a ele (Boécio, 1978, Livro IV, [1205C-1206C, 20-27], p. 79, tradução nossa). ${ }^{5}$

Dado que um Tópico Dialético utiliza um silogismo completo enquanto um Tópico Retórico utiliza um entimema, no silogismo retórico há a ausência de prova da ligação entre a premissa universal e a premissa particular que se realiza por meio do termo médio. Boécio considera que um entimema é "um método substituto para o silogismo" (cf. Boécio, Livro II, [1184B, 18-19], p. 45) na argumentação, pois trata-se de um silogismo imperfeito e, dessa forma, fica claro que ambos os tipos de Tópicos estão sob a mesma espécie de argumentação do silogismo. Boécio apenas identifica duas espécies, a saber, silogismos e induções.

Uma vez que em ambos os casos a construção do Tópico parte de um silogismo, um Tópico pode ter uma estrutura geral categórica ou hipotética. No entanto, sua base depende de sua Proposição Máxima ou Differentia. Acerca do que deve ser compreendido como uma Proposição Máxima, Boécio escreve:

Existem algumas proposições que não apenas são conhecidas propriamente, mas que, também, não possuem nada de mais fundamental pelo que elas são demonstradas e essas são chamadas [proposições] máximas ou principais. E existem outras para as quais as proposições primeiras e máximas oferecem crença. Então, de todas as coisas que são trazidas à consideração, as primeiras sobre as quais se concorda devem ser essas que providenciam crença para outras coisas, de tal forma que nada de mais conhecido pode ser encontrado. [...] Tal proposição está, às vezes, contida nos limites

4 Silogismos incompletos que possuem pelo menos uma proposição subentendida.

5 Tradução livre de: [...] if dialectic ever does admit circumstances, such as some deed or person, into the disputation, it does not do so for their own sake (principaliter), but it transfers the whole force of the circumstance to the thesis it is discussing. But if rhetoric takes up a thesis, it draws it into the hypothesis. Each investigates its own material but takes up that of the other so that the matter depends on the discipline more suited to it. BOÉCIO. "De topicis differentiis". In: STUMP, E. (trad.). Boethius's De topicis differentiis, 1978, Livro IV, [1205C-1206C, 20-27], p. 79. 
de um argumento e, às vezes, dá força ao argumento e o completa de fora ${ }^{6}$ (Boécio, 1978, Livro II, [1185A-1185B, 21-37], p. 46, tradução nossa).

Assim, mesmo um Tópico Retórico pode apresentar uma Proposição Máxima apesar de seu status de silogismo imperfeito, pois é dela ou de sua Differentia que ele retira sua força argumentativa, ainda que não precise buscar nelas o meio termo para a formação de um silogismo perfeito como acontece no caso de um Tópico Dialético. Quanto a Differentia, podemos entender aquilo que, de fato, dá força ao tópico, pois, na leitura boeciana, "[...] ainda que seu principal interesse esteja nas Differentiae [...]"7 (Stump, 1978, p. 180), ele escolheu começar com o que entende como sendo o método tradicional aristotélico por meio da utilização das Proposições Máximas (cf. Stump, 1978). Uma Differentia é aquilo que permite encontrar o termo médio do Argumento Tópico e do que, portanto, a própria inferência é dependente. No entanto, ela não indica um termo médio específico, mas, sim, a forma que o termo médio poderia ter, de modo que, dado o conteúdo do argumento, torna possível encontrá-lo.

Mais do que isso, Tópicos Retóricos seguem a fórmula do discurso retórico, pois "[...] todas as partes da retórica estarão em todas as espécies de retórica" (Boécio, Livro IV, [1208A, 14-15] p. 82, tradução nossa). Dessa forma, esperase do discurso retórico que apresente exórdio, narrativa, probatio, confirmação, refutação e peroração. Sem que todas as partes da retórica estejam presentes no discurso retórico, não se pode chamar aquele discurso como tal, pois suas partes devem estar presentes em todas as suas espécies que são três, a saber, deliberativa, epidítica e judicial.

Quando as espécies entram no assunto, isto é, na questão política, e tendo sido obtidas com suas partes, elas trazem com elas a própria disciplina retórica. Assim, as partes de retórica, também, estarão nas questões individuais. Uma vez que a questão tenha sido produzida, ela traz com ela o seu instrumento e, por isso, traz consigo o discurso que traz com ele suas próprias partes. E, assim, as questões a serem discutidas terão exórdio, narração e todo o resto (Boécio, 1978, Livro IV, [1211D, 4-11], p. 88, tradução nossa). ${ }^{9}$

6 Tradução livre de: There are some propositions which not only are known per se but also have nothing more fundamental by which they are demonstrated, and these are called maximal and principal [propositions]. And there are others for which the first and maximal propositions provide belief. So of all things which are brought into question, the very first to be agreed to must be those which can provide belief for other things in such a way that nothing more known than they can be found. [...] Such a proposition is sometimes contained within the boundaries of an argument, and sometimes it supplies force to the argument and makes [it] complete from without. BOÉCIO. "De topicis differentiis". In: STUMP, E. (trad.). Boethius's De topicis differentiis, 1978, Livro II, [1185A-1185B, 21-37], p. 46.

7 Tradução livre de: [...] even though his main interest is in the Differentiae [...] (Stump, 1978, p. 180).

8 Tradução livre de: [...] all parts of rhetoric will be in the species of rhetoric. BOÉClO. "De topicis differentiis". In: STUMP, E. (trad.). Boethius's De topicis differentiis, 1978, Livro IV, [1208A, 14-15], p. 82.

9 Tradução livre de: When the species have come into the matter, that is, into the political question, and have obtained it with its parts, they bring with themselves also the rhetorical discipline itself. So the parts of rhetoric 
Cabe ressaltar que a utilização de Tópicos Retóricos não implica a ausência de Tópicos Dialéticos, mas que o discurso no qual os Tópicos Dialéticos estão inseridos tem um propósito legal ou político. Isso se dá porque um tópico sempre pressupõe o aparato comum ao silogismo, de modo que ambos os tipos utilizam, em sua forma mais básica, proposições que são universais, particulares ou indefinidas, e são de tipo ou predicativo ou condicional, dado que estão inseridos nesse gênero independentemente de se apresentarem como silogismos completos ou incompletos. Um tópico sempre trata de uma proposição posta em dúvida, de modo que, em sua forma mais básica, um Argumento Tópico parte do aparato silogístico a fim de formular uma questão de modo correto para, apenas então, encontrar um termo médio e, consequentemente, um argumento que responda a essa questão. No caso dos Tópicos Retóricos, a descoberta se dará por meio dos atributos da pessoa e ação envolvidos no caso, pois será pelo caso que será possível encontrar a Proposição Máxima ou Differentia.

Ainda, pode-se dizer que a principal diferença entre Tópicos Dialéticos e Retóricos advém do modo como Boécio identifica e utiliza os predicáveis, pois Tópicos Retóricos focam em coisas de natureza particular, de modo que não consideram acerca daquilo que é maior do que a natureza do sujeito, como, por exemplo, gênero. Dessa forma, há uma limitação quanto às Differentiae que podem ser aplicadas a casos retóricos. Gênero, no entanto, é um predicável que diverge de definição e differentia, de modo que sua exclusão de aplicação quanto à retórica significa apenas que tais argumentos estão restritos ao gênero particular daquilo que se argumenta. No caso de homem, trata-se de um homem particular e não do gênero homem, como, por exemplo, Cálias ou Sócrates. Isso se dá por tratar-se do gênero particular da coisa em questão, no caso, o gênero particular do gênero homem, que é algo particular e que pode ser tomado como questão em consideração sob qualquer uma das espécies da retórica. No caso das differentiae, entende-se que há uma distinção entre a Differentia que ajuda a encontrar argumentos e aquela differentia que Porfírio identifica como predicável. Ainda que a teoria das Differentiae esteja baseada na teoria dos predicáveis, é importante ter em mente que esses termos significam coisas distintas.

\subsection{O Itinerário da Consolação e os Argumentos Tópicos}

Ainda que não se encontre na "Consolação" a forte característica autobiográfica que esperaríamos após a modernidade (cf. Savian Filho, 2005),

too will be in the individual issues. Once the matter has been produced, it brings with it its instrument; so it brings with it discourse, and discourse brings with it its own parts. And so in the issues to be discussed there will be exordium, narration, and the rest (Ibidem, Livro IV, [1211D, 4-11], p. 88). 
a obra estabelece o contexto em que a morte do autor ocorre e, consequentemente, a razão pela qual ele escreve e busca consolo. Ainda que o gênero consolatio pressuponha um tipo de escrita capaz de "[...] se engajar na comunicação de forma tão efetiva que capture a atenção e o interesse do destinatário"10 (Agrell, 2015 , p. 11, tradução nossa), é mediante certo apelo retórico que podemos reconhecer no método utilizado por Boécio as características que o próprio autor aponta para o uso de Argumentos Tópicos Retóricos. Mesmo que o conteúdo da obra se dê por meio um tipo de discurso mais apropriado para o uso de Tópicos exclusivamente Dialéticos, a obra, como um conjunto completo, pode ser considerada como discurso ininterrupto. ${ }^{11}$ Inclusive, há partes dela nas quais ao personagem do autor é permitido fazer tal tipo de discurso sem que a Filosofia o interrompa, aguardando que ele termine sua colocação antes de fazer sua réplica.

\subsubsection{Tópicos Retóricos}

Conforme a posição defendida por Edmund Reiss e reforçada por Nathan Basik, mesmo que a "Consolação", como um todo, não corresponda aos moldes retóricos, é possível encontrar nela o formato que Boécio exige de tal discurso já no Livro I, Prosa IV.

Como aponta Reiss, a seção autobiográfica cai na tradicional divisão de cinco partes da oratória de Quintiliano. No exórdio, Boécio afirma que sua desgraça não é merecida, a fim de obter a simpatia do leitor. Em segundo lugar, a narração inclui casos passados com os quais ele alega 'que ele sempre se opôs a injustiça'. Boécio afirma que ele foi acusado injustamente, na probatio. Na refutação, ele ataca as testemunhas do caso contra ele. Finalmente, na peroração, Boécio generaliza seu caso para um estado universal de coisas no qual os inocentes são 'roubados não apenas de sua paz e segurança, mas de qualquer chance de defenderem a si mesmos' (Basik, 2000, p. 06, tradução nossa). ${ }^{12}$

O discurso em questão é realizado de forma ininterrupta enquanto o personagem da Filosofia aguarda silenciosamente que Boécio (personagem) termine sua

10 Tradução livre de: [...] to create an effective addressivity that catches the attention and interest of the addressee (Agrell, 2015, 4, p. 11).

11 Defendo isso de modo mais aprofundado no estudo que propus em "AArte do Discurso: algumas considerações sobre o possível uso de argumentos tópicos retóricos na Consolação da Filosofia". Parvae Notitiae de Medio Aevo, pp. 45-62.

12 Tradução livre de: As Reiss points out, the autobiographical section falls into a traditional, five part division of oration" familiar from Quintillian. In the exordium, Boethius claims his misfortune is undeserved, to make the reader sympathetic. Second, the narration includes past cases, by which he claims "he has always opposed injustice." Boethius asserts he was wrongly accused, in the probatio. In the refutatio, he attacks the witnesses against him. Finally, in the peroratio, Boethius generalizes his case to the universal state of affairs, in which the innocent are "robbed not merely of their peace and safety, but even of all chance of defending themselves" (Basik, 2000, p. 06). 
fala. O ponto em questão é apresentado exatamente nos moldes que Boécio propõe em "De topicis differentiis". Assim, estabelecida a conexão com o uso de Tópicos Retóricos, resta saber qual a espécie de Tópicos que Boécio está utilizando na argumentação com a Filosofia.

Como dito anteriormente, as espécies de Tópicos retóricos são três (política ou deliberativa, epidítica e jurídica) e cada uma delas é, ela mesma, um gênero de casos com características próprias e reconhecíveis. Sendo elas os tipos de discurso retórico, nessas espécies deve-se encontrar toda a retórica, assim como nas partes da retórica encontra-se a própria disciplina da retórica (cf. Boécio, Livro IV, 1978, [1211D, 4-11], p. 88). Toda divisão de Tópicos retóricos é dependente da pessoa e da ação, pois "[a] pessoa é aquela que é trazida a julgamento, com algum feito ou discurso censurado. A ação é o feito ou discurso pelo qual a pessoa é trazida a julgamento. Toda divisão dos Tópicos inclui esses dois"13 (Boécio, 1978, Livro IV, [1211D, 29-31], p. 88, tradução nossa). Assim, Boécio também considera, ao dividir os Tópicos retóricos, aqueles que dizem respeito à pessoa e aqueles que dizem respeito à ação, podendo cada um deles pertencer a uma espécie de retórica. Cabe diferenciar primeiro questões internas e externas a documentos, pois:

As differentiae de problemas externos a documentos e apresentados em disputas sobre as coisas elas mesmas são divididas de acordo com a diversidade da natureza das coisas elas mesmas, pois cada questão retórica que está em dúvida é sobre o que é, que tipo de coisa é, quais as qualidades que tem e, em adição a isso, se julgamento legal ou moral pode ser administrado ${ }^{14}$ (Boécio, 1978, Livro IV, [1209C, 26-32], p. 84, tradução nossa).

Disso, considera-se, a partir de como Boécio divide o gênero dessas questões, que questões externas a documentos são ou de tipo jurídicas e tratam do que está no passado, ou de tipo legal e tratam do que está no presente ou do que virá a ser, estando no futuro. Uma vez que seu texto, na "Consolação", trate de um caso já encerrado, cuja condenação era inclusive conhecida e esperada, podemos considerar que Boécio está tratando de uma questão externa a documentos e de assuntos no passado, sendo, portanto, uma argumentação Tópica Retórica de espécie jurídica.

13 Tradução livre de: The person is the one brought to trial, some deed or speech of whose is censured. The action is the person's deed or speech for which he is brought to trial. Every division of Topics is comprised in these two (BOÉCIO. "De topicis differentiis". In: STUMP, E. (trad.). Boethius's De topicis differentiis, 1978, Livro IV, [1211D, 29-31], p. 88.

14 Tradução livre: The differentiae of the issues external to documents and put forth in dispute about things themselves are divided according to the diversity of the nature of the things themselves, for in every rhetorical question what is in doubt is whether it is, what kind of thing (quid) it is, what qualities it has, and in addition, whether judgment can be lawfully or morally administered (Ibidem, Livro IV, [1209C, 26 -32], p. 84). 
Dos tipos de argumentação jurídica, o autor reconhece dois: "Ou a força da defesa está na própria ação e a qualidade é chamada 'absoluta'; ou a força da defesa é assumida de fora e o tipo é chamado "hipotético""15 (Boécio, Livro IV [1210A, 14-17, p. 85, tradução nossa). O tipo hipotético divide-se em quatro outros tipos conforme a variedade de crime cometido e o nível e o tipo de justificação por parte do sujeito. Das partes do tipo jurídico hipotético, a saber, reconhecida, removida, transferida e comparada, parece ser o caso que o discurso boeciano recorre a todos eles para justificar sua situação na Prosa IV, provando a injustiça de sua situação por meio de todas as partes do discurso retórico jurídico hipotético.

Uma vez que ele aponta a corrupção do Senado, contra quem ressalta frequentemente que se opunha, Boécio estaria argumentando que, mesmo que um delito tenha sido cometido, teria sido "[...] cometido justamente contra alguém, já que aquele contra quem foi cometido era frequentemente injusto e merecia sofrer tal cobrança""16 (Boécio, 1978, Livro IV, [1210B, 37-39], p. 85, tradução nossa). Seria, nesse caso, um crime transferido. No entanto, Boécio também argumenta que o que lhe foi feito, foi feito devido ao poder exercido por outros, tendo ele sido traído por informantes apesar de seu amor pela justiça. Parece ser o caso de que Boécio tenta argumentar que o crime deveria, também, ser removido, pois o que fez, fez por justiça e só está sofrendo as consequências devido ao que outros, pouco confiáveis, fizeram.

É dito que eu desejei a segurança do Senado. Sabes como? Eu sou acusado de impedir um informante de trazer documentos segundo os quais ele faria do Senado culpado de traição. Então, minha professora, o que pensas? Devo negar a denúncia, a fim de não ser um embaraço para ti? Mas eu, de fato, queria a segurança do Senado e tampouco eu cessarei de querê-la. Devo confessar? Mas não houve esforço para impedir um informante. Ou devo eu chamar o desejo pela segurança da ordem senatorial um crime? Certamente, por seu decreto contra mim, o Senado reconhece que isso é um crime. Mas tal temeridade, que se encontra a si mesma, não pode mudar os méritos das coisas, e não penso, de acordo com o decreto de Sócrates, que é certo para mim nem esconder a verdade nem ser conivente com mentiras ${ }^{17}$ (Boécio, Livro I, Prosa IV, 20-25, p. 11, tradução nossa).

15 Tradução livre de: Either the force of the defense is in the deed itself, and the quality is called 'absolute'; or the force of the defense is assumed from without, and the issue is called 'assumptive' (Ibidem, Livro IV [1210A, 14-17], p. 85)

16 Tradução livre de: [...] justly committed against someone since the one against whom it was committed was often unjust and deserved to suffer what it is charged [that the defendant did] (BOÉCIO. "De topicis differentiis". In: STUMP, E. (trad.). Boethius's De topicis differentiis, 1978, Livro IV, [1210B, 37-39], p. 85.

17 Tradução livre de: It is said that I desired the safety of the Senate. Do you want to know how? I am accused of blocking an informer from bringing documents by which he would have it that the Senate was guilty of treason. So, my teacher, what do you think? Shall I deny the charge, so as not to be an embarrassment to you? But I did want the Senate's safety, nor will I ever cease to want it. Shall I admit to it? But there was no effort to 
Por fim, Boécio compara seu crime e conforme ele escreve: "Removido quase quinhentas milhas, sem voz e sem defesa, estou condenado à morte e ao confisco por causa de minha preocupação excessiva com o Senado"18 (Boécio, 2001, Livro I, Prosa IV, 40-43, pp. 12-13, tradução nossa). Ele também parece reconhecê-lo, utilizando necessidade como seu argumento:

Você se lembra, eu acredito - afinal estavas constantemente ao meu lado, guiando-me sempre que eu ia dizer algo ou fazer algo - como eu estava dizendo, você se lembra daquela vez em Verona: Com forte descaso para com o perigo em que me encontrava, levantei-me para defender a inocência de todo aquele corpo perante o rei, impaciente por nossa ruína universal, que tentou fazer da acusação de traição que tinha sido feita contra Albino uma acusação contra toda a ordem senatorial (Boécio, 2001, Livro I, Prosa IV, 32, p. 12, tradução nossa). ${ }^{19}$

Ainda que Boécio argumente retoricamente como culpado de um crime, argumenta de forma que a culpa desse crime não deveria ser utilizada contra ele. Especificamente, ele argumenta que é uma injustiça que utilizem tal culpa a ponto de levar a uma condenação tão extrema quanto a que o aguarda. A estrutura que utiliza para sua argumentação dá força ao conteúdo dela, de modo que se pode dizer que Boécio opõe-se veementemente à condenação quando a expõe ao personagem da Filosofia.

Boécio, também, segue o gênero da consolatio de modo esperado, oferecendo conselhos para que o leitor/ouvinte possa superar adversidades que ele próprio não poderá mais superar, pois, por meio de seus estudos e de seus últimos momentos de contemplação, encontrou um caminho que poderia ajudar o leitor. Mais do que isso, o autor aponta como tais adversidades não são sequer reconhecidas como assim sendo por aqueles que as encontram, de modo que é parte do itinerário da obra o convencimento, ou seja, a produção de crença sobre a ideia de que os bens oferecidos pela fortuna são bens ilusórios e que aqueles que dela dependem encontram apenas infortúnios. É nessa argumentação

block the informer. Or shall I call the desire for the safety of the senatorial order a crime? To be sure, by its decrees against me the Senate has brought it about that this is a crime. But such temerity, which always lies to itself, cannot change the merits of things, and I do not think, in accordance with the decree of Socrates, that it is right for me either to hide the truth or to connive at lies (BOÉCIO. "Consolation of Philosophy", 2001, Livro I, Prosa IV, 20- 25, p. 11).

18 Tradução livre de: At a remove of nearly five hundred miles, without voice and without defense, I am condemned to death and confiscation because of my overzealous concern for the Senate (Ibidem, 40-43, pp. 12-13).

19 Tradução livre de: You do remember, I think—after all you were yourself constantly at my side, steering me whenever I was going to say something or do something-as I was saying, you do remember that time at Verona: With what bold disregard for my own peril I stood up for the innocence of that entire body when the king, who was impatient for our universal downfall, tried to turn the charge of treason that had been made against Albinus against the entire senatorial order (Ibidem, 32, p. 12). 
e na argumentação do que são os verdadeiros bens que podemos encontrar Argumentos Tópicos Dialéticos.

\title{
1.2.2 Tópicos Dialéticos
}

Sendo que a contemplação da verdade é a única coisa que impediria o homem de se sujeitar às inconstâncias da fortuna, distinguir o que é ou não o verdadeiro bem passa a ser um ponto fundamental da obra. Dessa forma, iniciamos nossas considerações acerca do uso de Tópicos Dialéticos no Livro III, onde Boécio considera as inconstâncias dos bens da Fortuna.

No Livro III, Prosa III, Boécio, por intermédio da Filosofia, questiona: "Em meio a toda sua riqueza e seus recursos extravagantemente abundantes, sua mente nunca foi atordoada por uma irritação nascida de um insulto ou outro?"20 (Boécio, 2001, Livro III, Prosa III, 5, p. 55, tradução nossa). A partir desse questionamento, podemos encontrar um argumento fundamentado na Differentia de definição com a Proposição Máxima que diz que coisas com definições diferentes são elas mesmas diferentes. Sendo a felicidade autossuficiente, a riqueza, caso fosse a felicidade, deveria ser, também, autossuficiente. Como não é parte da definição da riqueza ser autossuficiente, podemos encontrar um argumento a partir da Differentia apontada. Mais do que isso:

\begin{abstract}
Portanto, a riqueza não é capaz de fazer uma pessoa não ter falta de nada e ser autossuficiente, ainda que seja isso o que parece prometer. E, no entanto, penso que esse ponto mais profundo e importante também precisa ser observado, o fato de que o dinheiro não tem em [sua natureza] e que é de sua própria natureza ter nada que possa impedi-lo de ser tomado contra a vontade de quem possuí-lo ${ }^{21}$ (Boécio, 2001, Livro III, Prosa 3, 11-12, p. 56, tradução nossa).
\end{abstract}

Há que se considerar, ainda, que a felicidade não pode ser tomada daqueles que a possuem, conforme Boécio discorre no Livro II, mas, aqui, o mesmo não é dito da riqueza. Assim sendo, por ser da natureza da riqueza poder ser tomada de outros, a riqueza não pode ser o mesmo que a felicidade por, novamente, possuir uma definição diferente daquela que é a definição da felicidade.

De modo similar, Boécio considera a superioridade política e, também, conclui que ela não é suficiente para alcançar a verdadeira felicidade, sendo mais

20 Tradução livre de: In the midst of all your extravagantly abundant wealth and resources, was your mind never dazed by a fretfulness born of some insult or other? (Boécio. "Consolation of Philosophy", 2001, Livro III, Prosa 3, 5, p. 55).

21 Tradução livre de: Therefore, wealth is not able to make a person lack for nothing and be self-sufficient, yet this is what it seemed to promise. And yet, I think that this further and most important point also needs to be looked at, the fact that money has in and of its own nature nothing that can keep it from being taken away from those who possess it against their will (Ibidem, Livro III, Prosa 3, 11-12, p. 56). 
um bem da fortuna. $\mathrm{O}$ autor aponta que esse tipo de superioridade não garante que as honras sejam dadas apenas àqueles que sejam merecedores e, portanto, não há garantias de que aqueles que as recebem são eles mesmos merecedores de tais honrarias. A felicidade, no entanto, só é alcançada por aqueles que são merecedores dela, de modo que a mesma Differentia pode ser usada muitas vezes para formular silogismos similares. Esse também é o caso do poder, pois o poder não se mantém eternamente. Em ambos os casos, Boécio aponta, ainda, que a autossuficiência, característica da felicidade, não é uma propriedade das honrarias políticas ou do poder. No entanto, cabe ressaltar que não é o caso de que apenas a Differentia de definição seja usada, pois ele parece argumentar, aqui, segundo a Differentia de opostos com referência à privação e possessão. A Proposição Máxima utilizada seria que "[...] onde a privação pode estar presente, a posse não é uma propriedade"22 (Boécio, 1978, Livro II, [1191C-1191D], 2122 , p. 56, tradução nossa), de modo que, onde a privação de poder, de riqueza e de honrarias pode estar presente, sua posse não é uma propriedade. A posse da felicidade é sempre uma propriedade do homem, sendo sempre possível a ele alcançá-la enquanto o mesmo não ocorre com os bens da fortuna. Dessa forma, ainda que a felicidade pareça ser uma consequência de tais coisas, os bens da fortuna acima apontados não podem garantir a autossuficiência que caracteriza a completude da verdadeira felicidade.

Quanto ao nascimento nobre, ainda que não possua a possibilidade de ser tomado por outrem como ocorre com os demais bens da fortuna, ele também não possui em si mesmo a propriedade de ser virtuoso. Boécio argumenta que a virtude não pertence ao nobre apenas por sua nobreza e, consequentemente, as honrarias dedicadas à virtude não lhe devem ser reservadas apenas por causa de seu nascimento. Podemos encontrar aqui um raciocínio que está de acordo com a Differentia de acidentes associados cuja Proposição Máxima é “[...] o que segue de algo (consequens) que não pertence a alguma coisa não pode, tampouco, pertencer na coisa"23 (Boécio, 1978, Livro II, [1190B], 17-19, p. 54, tradução nossa). Nesse caso, uma vez que as honrarias não podem pertencer ao nascimento nobre sem virtude, a felicidade que poderia se seguir disso, também, não pertence à nobreza sem virtude. Também quanto aos prazeres carnais, Boécio apresenta um argumento semelhante aos demais argumentos que utiliza para indicar que os bens da fortuna não são o verdadeiro bem, de modo que

22 Tradução livre de: [...] where the privation can be present, the possession is not a property (BOÉCIO. "Boethius's De topicis differentiis". STUMP, E. (trad.). De topicis differentiis, 1978, [1191C-1191D] 25-29, Livro II, p. 56).

23 Tradução livre de: [...] what follows from something (consequens) which does not inhere in a thing cannot inhere in that thing either (Ibidem, [1190B], 17-19, Livro II, p. 54). 
riqueza, honrarias, poder, glória e prazeres do corpo não satisfazem qualquer uma das condições para expressar o bem último que não deixa nada mais a ser desejado e não pode ser perdido devido a infortúnios ou roubado por outros.

Dessa forma, como apontado pela argumentação da Prosa V à VIII, Boécio deixa claro que a definição de felicidade não é a mesma que a definição dos bens da fortuna considerados até aqui, de modo que a felicidade e os bens da fortuna não podem ser a mesma coisa. Conforme Boécio escreve:

E eu vejo isso, eu disse; a autossuficiência não pode ser uma propriedade de riqueza e recursos, nem pode o poder ser uma propriedade de reinos, nem preeminência [uma propriedade] dos altos cargos, nem aclamação da glória, nem deleite dos prazeres físicos ${ }^{24}$ (Boécio, 2001, Livro III, Prosa 9, 2, p. 67, tradução nossa).

Tais bens não podem ser sequer expressões da felicidade, pois a felicidade não é uma propriedade deles, de modo que esses aspectos que parecem causar ou, até mesmo, ser a felicidade não são aspectos da coisa com a qual são identificados, mas, sim, percebidos como tais devido aos erros humanos.

Ao considerar que a perfeição de Deus exige que não exista nada melhor que ele e o bem supremo é encontrado em Deus, consequentemente, a felicidade também é encontrada em Deus, pois a felicidade é o bem supremo e o bem supremo é a felicidade. Assim, “[...] estabelecemos que a verdadeira felicidade é o Bem maior; logo, é necessário que a verdadeira felicidade seja encontrada no Deus maior" 25 (Boécio, 2001, Livro III, Prosa 9, 10, p. 74, tradução nossa). É importante apontar que, se a felicidade e o bem possuem a mesma definição, são, necessariamente, a mesma coisa, e é impossível que apenas o bem seja encontrado em Deus, pois coisas com definições diferentes seriam elas mesmas diferentes e, nesse caso, ambas as coisas possuem a mesma definição e devem ser uma e a mesma. Boécio até utiliza a Proposição Máxima do tópico de definição que justifica tal conclusão, a saber, que "[a]quilo que é diferente de qualquer outra coisa não é ela mesma o que é entendido por aquilo que ela é diferente de"26 (Boécio, 2001, Livro III, Prosa 9, 15, p. 74, tradução nossa). Não sendo o caso que tais coisas tenham definições diferentes, não há razão para que não sejam a mesma coisa. Boécio aceita a equivalência a ponto de afirmar que, uma

24 Tradução livre de: And I do see it, I said; self-sufficiency can't possibly be a property of wealth and resources, nor can power be a property of kingdoms, nor preeminence of high offices, nor acclamation of glory, nor delight of physical pleasures (BOÉCIO. "Consolation of Philosophy", 2001, Livro III, Prosa 9, 2, p. 67.

25 Tradução livre de: [...] we have established that true happiness is the highest Good; therefore, it is necessary that true happiness is located in this highest God (Ibidem. Livro III, Prosa 9, 10, p. 74).

26 Tradução livre de: That which is different from any other thing is not itself the same as what it is understood to be different from (Ibidem, Livro III, Prosa 9, 15, p. 74). 
vez que se assegure a felicidade, também se assegura a divindade, pois, sendo ambas a mesma coisa, uma não pode acontecer sem a outra.

Conforme o próprio filósofo aponta, todas as conclusões obtidas em tais argumentos derivam de algo intrínseco àquilo que está sendo argumentado, não dependendo de qualquer outra coisa além de si mesmo. O que a Differentia e a Proposição Máxima proporcionam aos silogismos que podem ser encontrados por meio do tópico é força argumentativa.

E quanto ao fato de que repetidamente usamos argumentos que não foram externamente procurados, mas que [estão] dentro dos limites do tema que estávamos discutindo, não há nenhuma razão para surpresa, afinal, aprendeu-se, como Platão declarou, que o discurso deve ser estreitamente relacionado com os tópicos que ele aborda ${ }^{27}$ (Boécio, 2001, Livro III, Prosa 12, 38, p. 88, tradução nossa).

A demonstração do próprio silogismo não é necessária, pois, uma vez que se indique a Differentia ou a Proposição Máxima, qualquer um versado na arte dos tópicos seria capaz de formular o argumento correto que está implícito a partir deles. Assim, Boécio pretende estabelecer que seus argumentos são adequadamente fortes e plausíveis, seguindo regras lógicas que regem a descoberta de argumentos, bem como a própria argumentação quanto à utilização desses argumentos.

A obra ressalta, diversas vezes, que, ainda que algo não pareça plausível por si só, certas verdades acerca do universo tornam necessária a organização de tudo que existe. Sendo Deus bom, o universo é bom, e sendo o universo bom, é pouco razoável assumir que o universo seria injusto, permitindo que os maus fossem recompensados e os bons punidos. Portanto, a organização correta do universo deve se dar de uma forma que contemple tal explicação, ainda que outra explicação seja mais intuitiva, de modo que o que Boécio pretende é inspirar crença sobre as conclusões às quais chega por meio da filosofia. A Filosofia (personagem) insiste que Boécio não duvide das conclusões a que chega, pois tais conclusões são obtidas à medida que ele (o personagem do autor) volta a contemplar a verdade, o que torna, de certa forma, as conclusões do próprio Boécio, topicamente mais plausíveis.

A finalidade, às vezes, está no próprio orador e, às vezes, no outro. [Quando está] no próprio orador, [a finalidade] é ter falado bem, ou seja, ter falado de um modo

27 Tradução livre de: And as to the fact that we have repeatedly used arguments that were not externally sought but within the bounds of the topic we were discussing, there is no reason for you to be amazed-after all, you have learned, as Plato has decreed it, that discourse ought to be closely related to the topics that it addresses (Ibidem, Livro III, Prosa 12, 38, p. 88). 
apropriado à persuasão; [quando está] no outro, é ter persuadido. Não é o caso que se atrapalharem o orador de forma que ele persuada menos como resultado, o fim não tenha sido atingido, quando a função foi executada. A finalidade que está próxima e relacionada com o fim que é externo, todavia, frequentemente não é atingida. Mas a retórica, que se esforçou para seu fim, não está, assim, privada de [sua] honra ${ }^{28}$ (Boécio, 1978, Livro IV, [1208D-1209A, 22-33], p. 83, tradução nossa).

Logo, no caso da "Consolação" como um todo, Boécio parece ter atingido seu objetivo, ao menos enquanto retórico, e persuadido alguns, em certa medida, dialeticamente.

\section{Considerações finais}

Enquanto Inferências Tópicas Dialéticas não consideram as circunstâncias, Argumentos Tópicos Retóricos baseiam-se nelas, e, mesmo que apenas argumentos Tópicos Dialéticos busquem responder perguntas em um formato que antecipa os moldes escolásticos, ambos os tipos de inferência representam o gênero de Argumentos Tópicos, sendo espécies dele. Quando Boécio utiliza tanto um quanto o outro, ele está pressupondo o mesmo aparato teórico, pois o gênero de argumentação tópica baseia-se na teoria silogística e, consequentemente, na interpretação boeciana da teoria dos predicáveis. Dessa forma, uma vez que Boécio utilize Argumentos Tópicos, é, até mesmo, necessário, que se compreenda como ele aplica a interpretação harmonizada que faz dos predicáveis aristotélicos e porfirianos, a fim de compreender seus escritos por completo. Mais do que isso, a partir de sua interpretação, a utilização de tais argumentos assume um modelo que não deveria ser lido desconsiderando a formulação boeciana de como esses argumentos funcionam. Na "Consolação", parece ser o caso que Boécio recorre aos Argumentos Tópicos para dar força às inferências que pretende utilizar na argumentação com a Filosofia (personagem), buscando fora da própria argumentação aquilo que justifica o silogismo no qual seu ponto se baseia ou que, por vezes, parece ser o próprio argumento. Isso, no entanto, não é estranho na utilização dos Tópicos, cujo objetivo é produzir crença por meio de argumentos plausíveis que o ouvinte seja capaz de reconhecer como mais adequados que aqueles produzidos pelo oponente do orador em questão.

28 Tradução livre de: The end is sometimes within the orator himself and sometimes within another. [When it is] within the orator himself, it is to have spoken well, that is, to have spoken in a way appropriate for persuasion; [when it is] within another, it is to have persuaded. For it is not the case that if they hinder the orator in such a way that he persuades the less as a result, the end has not been achieved, when his function has been performed. The end which was near and related to the end which is external, however, often is not achieved. But, rhetoric, which has striven for its end, is not thereby deprived of [its] honor (BOÉCIO. "De topicis differentiis". In: STUMP, E. (trad.). Boethius's De topicis differentiis, 1978, Livro IV, [1208D-1209A, 22-33], p. 83). 
A estrutura da "Consolação", no entanto, ainda permite que o leitor identifique algumas das intenções do autor, uma vez que a utilização de Tópicos Retóricos nesta obra é uma leitura possível dela. Tal leitura apontaria para a "Consolação", ou ao menos parte dela, tendo sido escrita com o objetivo de ser lida como um texto político.

\section{Referências}

AGRELL, Beata. "Consolation of Literature as Rhetorical Tradition: Issues and Examples". Lir. Journal, 4, p. 10-35. 2015.

BASIK, N. "The Guilt of Boethius". 25 de Agosto de 2000. [Online] Disponível em: http://pvspade.com/Logic/docs/GuiltOfBoethius.pd> (Acessado em 20 Jan. 2018).

BIRD, O. "The formalizing of the topics in mediaeval logic". Notre Dame Journal of Formal Logic, Vol. 1, Nr. 4, pp. 138-149, 1960.

BOÉCIO. "Consolation of Philosophy". J. C. Relihan (ed. e trad.). Indianapólis/ Cambridge: Hackett Publishing Company, 2001.

BOÉCIO. "De topicis differentiis". In: STUMP, E. (trad.). Boethius's De topicis differentiis. Ithaca: Cornell University Press, 1978.

BOÉCIO. "In Ciceronis topica". In: STUMP. E. (ed. e trad.). Boethius's In Ciceronis topica: an annotated translation of a medieval dialectical text. Ithaca: Cornell University Press, 1988.

LIEBESCHÜTZ, H. "Boethius and the Legacy of Antiquity". In: ARMSTRONG, A. H. (ed). The Cambridge History of Later Greek and Early Medieval Philosophy. Cambridge: Cambridge University Press, 1967. p. 540.

MARENBON, J. "Boethius”. New York: Oxford University Press, 2003.

MARENBON, J. "Medieval Philosophy: An Historical and Philosophical Introduction". Cambridge: Cambridge University Press, 2007.

MARENBON, J. “The Cambridge Companion to Boethius”. Cambridge: Cambridge University Press, 2009.

SAVIAN FILHO, J. "Boécio e a Ética Eudaimonista". Cadernos de Ética e Filosofia Política, 7, pp. 109-127, 2/2005.

SPADE, P. V. (trad.). "Five Texts on the Mediaeval Problem of Universals: Porphyry, Boethius, Abelard, Duns Scotus, Ockham”. Indianapolis: Hackett, 1994.

SPADE, P. V. "A Survey of Mediaeval Philosophy. Version 2.0 - interim version". August 29, 1985. [Online] Disponível em: http://pvspade.com/Logic/docs/The $\% 20$ Course\%20in\%20the\%20Box\%20Version\%202_0.pdf (Acessado em 20 Jan. 2018). 